\title{
Inhaled corticosteroids improve lung function, airway hyper-responsiveness and airway inflammation but not symptom control in patients with mild intermittent asthma: A meta-analysis
}

\author{
WEI DU ${ }^{1}$, LING ZHOU ${ }^{1}$, YINGMENG NI ${ }^{1}$, YUANYUAN YU ${ }^{1}$, FANG WU $^{2}$ and GUOCHAO SHI ${ }^{1}$ \\ Departments of ${ }^{1}$ Pulmonary Medicine and ${ }^{2}$ Geratology, Ruijin Hospital, \\ Shanghai Jiao Tong University School of Medicine, Shanghai 200025, P.R. China
}

Received August 1, 2016; Accepted May 5, 2017

DOI: $10.3892 / e t m .2017 .4694$

\begin{abstract}
It remains controversial whether inhaled corticosteroid (ICS) should be used in patients with intermittent asthma. The present study aimed to assess the effect of ICS compared with placebo or other therapies in patients with intermittent asthma. Medline, Embase and CNKI databases were searched up to June 2016 and a meta-analysis was conducted. The findings demonstrated that in adult patients, when compared with placebo, ICS increased forced expiratory volume in $1 \mathrm{sec}$ FEV1 [standardized mean difference (SMD), 0.51; 95\% confidence interval (CI), 0.22-0.80] and alleviated airway hyper-responsiveness, which was indicated as log transformed PC20FEV1 (concentrations of methacholine when there was a fall in FEV1 $\geq 20 \%$; SMD, 0.87; 95\% CI, 0.60 to 1.14). ICS also reduced fractional exhaled nitric oxide (FeNO) levels [weighted mean difference (WMD), -12.57 parts per billion (ppb; a unit of NO concentration in exhaled air); 95\% CI -15.88 to $-9.25 \mathrm{ppb}$. However, symptom scores did not change after ICS treatment (SMD, -0.26 ; $95 \%$ CI, -0.52 to 0 ). When compared with leukotriene receptor antagonists (LTRA), ICS had no advantage in increasing FEV1 (WMD, 0.04 1; 95\% CI, -0.06 to 0.131 ), reducing sputum eosinophil percentage (WMD, $-6 \%$; $95 \%$ CI, -12.38 to $0.38 \%$ ) or symptom scores (SMD, 0.44; 95\% CI, -0.02 to 0.9 ). However, in child patients, ICS significantly $(\mathrm{P}<0.05)$ increased the possibility of symptom control when compared with placebo [relative risk (RR), 8; 95\% CI, 1.04 to 61.52 ] or LTRA (RR, 2.67; 95\% CI, 0.39 to 18.42 ). In
\end{abstract}

Correspondence to: Dr Guochao Shi, Department of Pulmonary Medicine, Ruijin Hospital, Shanghai Jiao Tong University School of Medicine, 197 Ruijin Er Road, Shanghai 200025, P.R. China

E-mail: shiguochao@hotmail.com

Dr Fang Wu, Department of Geratology, Ruijin Hospital, Shanghai Jiao Tong University School of Medicine, 197 Ruijin Er Road, Shanghai 200025, P.R. China

E-mail: wufangrjh@163.com

Key words: asthma, inhaled corticosteroids, meta-analysis, leukotriene receptor antagonists, clinical respiratory medicine conclusion, ICS improves lung function and alleviates airway hyper-responsiveness and airway inflammation but cannot influence symptom scores, and has no advantage over LTRA in terms of lung function improvement and airway inflammation control in adult patients with mild intermittent asthma. However, in children, the benefit of ICS in symptom control is more significant than with LTRA.

\section{Introduction}

Asthma is a common, chronic heterogeneous respiratory disease affecting 1-18\% of the population worldwide; in China it has a prevalence of $1.24 \%(1,2)$. Characterized by variable symptoms of wheezing, shortness of breath, chest tightness and/or cough, and by variable expiratory airflow limitation, asthma can be subdivided into four subcategories according to the severity of symptoms and airflow limitation, including mild intermittent, mild persistent, moderate persistent and severe persistent $(2,3)$.

Although $50-75 \%$ of asthma patients are categorized as having mild asthma, few studies have focused on these subtypes, particularly mild intermittent asthma (4). From the earliest to the latest guidelines, short acting $\beta 2$-agonist (SABA) as required is the only treatment recommended for patients with mild intermittent asthma, which is mostly based on expert opinions $(2,5)$. However, studies have shown that airway inflammation was also detected in patients with mild intermittent asthma, which may cause airway remodeling and disease progression $(6,7)$. This lead us to theorize the benefits and risks of the most important controller medication to date, inhaled corticosteroid (ICS), in these patients.

Hence the present meta-analysis aimed to analyze the effects of ICS on lung function, airway hyper-responsiveness (AHR), symptom control, airway inflammation and adverse effects in patients with mild intermittent asthma.

\section{Materials and methods}

Study selection criteria. Our inclusion criteria for considering studies for this review were as follows: i) Randomized controlled trials (RCT); ii) studies assessing patients with intermittent asthma that may be defined as using SABA 
only, few symptoms (daytime symptoms $\leq 2$ times/week and nocturnal symptoms $\leq 2$ times/month), forced expiratory volume in $1 \mathrm{sec}$ (FEV1) predicted $\geq 80 \%$, and peak expiratory flow (PEF) variability $\leq 20 \%$. For studies only describing some of these criteria and not implying other types of asthma, three independent researchers discussed and came to an agreement whether this study should be included; iii) ICS as the intervention compared with placebo or other therapies or ICS in combination with other therapies vs. other therapies alone; and iv) outcomes of studies reflecting lung function, AHR, airway inflammation, symptom control or adverse effects of the drugs in patients with intermittent asthma.

Exclusion criteria. We excluded studies that recruited mixed groups of participants (patients with mild intermittent and persistent asthma) and those that did not report the outcomes separately.

Search strategy and study selection. MEDLINE (https://www. ncbi.nlm.nih.gov/pubmed) and EMBASE (https://www.embase. $\mathrm{com} /$ ) databases were initially searched from inception to June 2016 using the following terms: i) 'asthma' OR 'antiasthma' OR 'anti asthma' OR 'respiratory sounds' OR 'wheez' OR ‘bronchial spasm' OR ‘bronchospasm' OR ('bronch’ AND 'spasm') OR ‘bronchoconstrict' OR ‘bronchoconstriction' OR ('bronch' AND 'constrict') OR ('bronchial hyperreactivity' AND 'respiratory hypersensitivity') OR ('bronchial' OR 'respiratory' OR 'airway' OR 'lung' AND ('hypersensitive' OR 'hyperreactiv' OR 'allerg' OR 'insufficiency') OR ('dust' OR 'mite' AND ('allerg' OR 'hypersensitiv'); ii) 'inhaled' AND 'corticosteroid' OR 'beclometasone' OR 'budesonide' OR ‘ciclesonide' OR 'fluticasone' OR 'mometasone' OR 'triamcinolone' OR 'ics'; and iii) 'mild' OR 'intermittent' OR 'infrequent'; iv) combination of points i, ii and iii mentioned above; iv) combination of point iv mentioned above and 'randomized controlled trial'.

China National Knowledge Internet (CKNI) database was also searched from inception to June 2016 using Chinese terms matched to the English terms outlined. Abstracts of citations resulting from this search were imported into a bibliographic database and hand-searched by two reviewers for duplicate publications, which were removed. Citations were initially excluded if it was clear that the study: i) Was not concerned with the treatment of chronic mild asthma in humans; ii) was not an RCT or iii) did not include a treatment arm with ICS.

Where uncertainty existed, the full text version of the publication was retrieved, and more detailed checks were conducted against our eligibility criteria. A third researcher evaluated the decision of inclusion or exclusion in discussion with the two reviewers. We also manually searched through the systematic reviews for any other articles that may be potentially suitable.

Study characteristics and data extraction. We used preformatted tables to record study design and participant characteristics, description of mild intermittent asthma, pharmacological agent (dose, device and frequency), and duration of follow-up. Two reviewers independently extracted data on relevant outcomes, including FEV1, forced vital capacity (FEV1/FVC), the concentration of methacholine when there was a fall in FEV1 $\geq 20 \%$ (PC20 FEV1), fractional exhaled nitric oxide (FeNO), number or percentage of sputum eosinophil and drug-related adverse effects. If an intention-to-treat analysis was not used by the researchers, and it was not shown in the results how many participants were in each group at the time of the final evaluation of that outcome, the number of patients in each group was calculated by subtracting the number of patients who discontinued or were lost to follow-up from those randomized to each group. Any discrepancies were resolved through the involvement of a third reviewer after rechecking the source papers.

Assessment of risk of bias. Two reviewers independently assessed the methodological quality of the included studies. The risk of bias was evaluated using the Jadad scale of 0-5 (8). Funnel plots were used to assess publication bias and sensitivity analyses were conducted using the highest quality studies (Jadad score $\geq 3$ ).

Statistical analysis. A pooled treatment effect across trials was calculated using RevMan 5.1.6 (Cochrane, UK). For continuous outcomes, a weighted mean difference (WMD) or standardized mean difference (SMD) was calculated, as appropriate. For dichotomous outcomes, a relative risk (RR) was calculated. Pooled treatments effects were expressed with their $95 \%$ confidence intervals $(95 \% \mathrm{CI})$. Heterogeneity of effect size across pooled studies was calculated. $\mathrm{P}<0.05$ was considered to indicate a statistically significant difference.

Statistical heterogeneity was assessed using the $\mathrm{I}^{2}$ statistic with $\mathrm{I}^{2}>50 \%$ indicating a substantial level of heterogeneity. In accordance with the recommendations of the Cochrane Handbook, we derived any standard deviations from $95 \%$ CIs or P-values (8). Measures of AHR, such as the provocative concentration of challenge substance required to produce $20 \%$ fall in FEV1 (PC20 FEV1) was often reported as geometric means, and data for such outcomes was pooled after the data was $\log$ transformed.

Sensitivity analyses were performed on the basis of methodological quality. Results were re-analyzed using studies of only the highest quality (Jadad scores 3-5). Subgroup analyses based on ICS treatment duration and patient age (children or adults) were conducted.

\section{Results}

Study characteristics and search results. In total, 838 potentially relevant articles were screened and 16 studies were included in this systemic review. The process of study selection is shown in Fig. 1. Of all the included studies, only one study (9) was conducted in children and the remaining 15 studies were conducted in adults (10-24). At the time of enrollment, the patients of the majority of studies were not treated with corticosteroids regularly. The ICS used in these studies included budesonide (BUD; 7 studies), fluticasone propionate (FP; 5 studies), and beclometasone dipropionate (BDP; 4 studies). The characteristics of studies are shown in Table I.

Study validity. Validity assessment of the studies is shown in Table II. The majority of studies had Jadad scores of $\geq 3$, with 


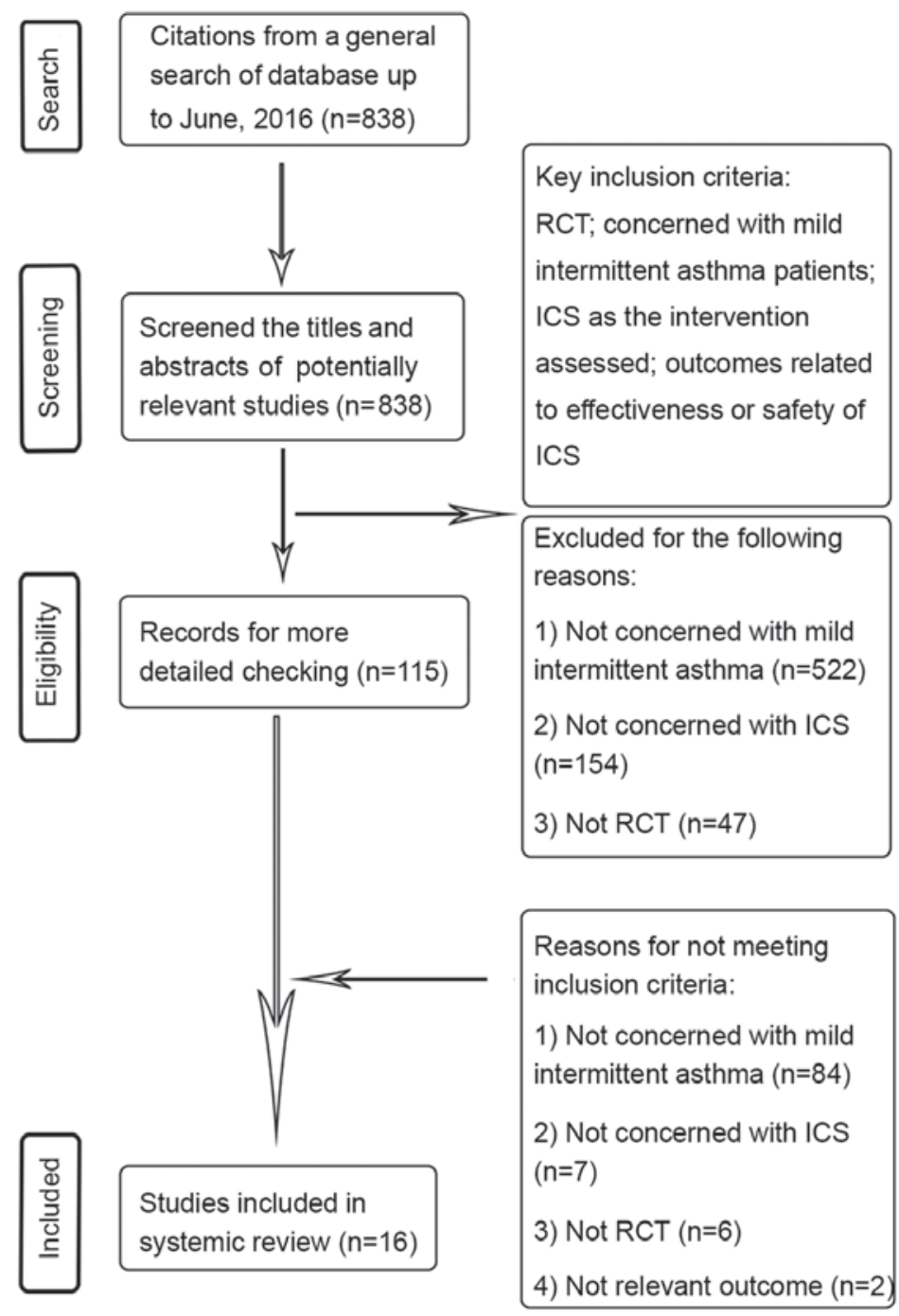

Figure 1. Flow diagram of study selection. ICS, inhaled corticosteroid; RCT, randomized controlled trial.

3 studies exhibiting scores $<3$. Similar results were observed after the exclusion of low quality trials (Jadad scores <3). Funnel plot analysis demonstrated that there may be publication bias in studies assessing FEV1 change, although this type of bias may exist in studies assessing other measurements due to the low number of studies (data not shown).

\section{Lung function}

FEV1. A significant improvement in FEV1 was noted after 3-6 months of ICS treatment vs. placebo (3 studies; SMD, $0.45 ; 95 \% \mathrm{CI}, 0.20$ to $0.71 ; \mathrm{I}^{2}=0 \%$; Fig. $\left.2 \mathrm{~A}\right)(14,16,22)$. Consistent with the results observed after 3-6 months of treatment, after 1 year of treatment, a further improvement in FEV1 was noted in the ICS groups as compared with placebo (2 studies; SMD, 0.86; 95\% CI, 0.34 to 1.39 ; $\mathrm{I}^{2}=15 \%$; Fig. 2A) (11,17). The overall effect of ICS on FEV1 change was also significant when compared with the effect of placebo (8 studies; SMD, 0.51; 95\% CI, 0.22 to $0.80 ; \mathrm{I}^{2}=49 \%$; Fig. 2A) $(10,11,13-17,22)$.

When compared with leukotriene receptor antagonists (LTRA), more than 2 months ICS treatment had no advantage on FEV1 improvement $(19,23)$ (2 studies; WMD, 0.041; 95\% CI, -0.06 to 0.13 ; $\mathrm{I}^{2}=0 \%$; Fig. $\left.2 \mathrm{~B}\right)$. All data were collected from adults, no studies measured FEV1 change or other lung function measurements in children.

PEF variability. A decrease of PEF variability was observed after 1 month of treatment with ICS compared with placebo $(10,21)$ (2 studies; WMD, $-2.54 \%$; $95 \%$ CI -4.99 to $-0.08 \%$; $\mathrm{I}^{2}=32 \%$; Fig. $\left.3 \mathrm{~A}\right)$. After 6 months of treatment, a further reduction of PEF variability was noted (22) (1 study; WMD, $-4.57 \%$; $95 \%$ CI, -4.92 to $-4.22 \%$ ). The overall effect of ICS treatment vs. placebo was also significant in PEF variability $(10,21,22)$ (3 studies; WMD, $-3.58 \%$; 95\% CI, -5.75 to $-1.41 \%$; $\mathrm{I}^{2}=78 \%$; Fig. 3A). Substantial heterogeneity $\left(\mathrm{I}^{2}=78 \%\right)$ in this meta-analysis may be explained by the small sample size of all 3 studies and the lower methodological quality of the study conducted by Stanković et al (22).

FEV1/FVC. Apparent change of FEV1/FVC could be seen after 6 months of treatment, while 1 year of treatment made no further difference (6 months, 1 study; WMD, 2.7\%; 95\% CI, 0.99 to $4.41 \%$ vs. 1 year, 1 study; WMD, $-0.2 \%$; $95 \%$ CI, -2.86 to $2.46 \%$; Fig. $3 \mathrm{~B})(11,22)$. The overall effect was not significant (2 studies; WMD, $1.44 \%$; $95 \%$ CI, -1.38 to 4.26 ; $\mathrm{I}^{2}=69 \%$; Fig. 3B). The heterogeneity $\left(\mathrm{I}^{2}=69 \%\right)$ of the meta-analysis 


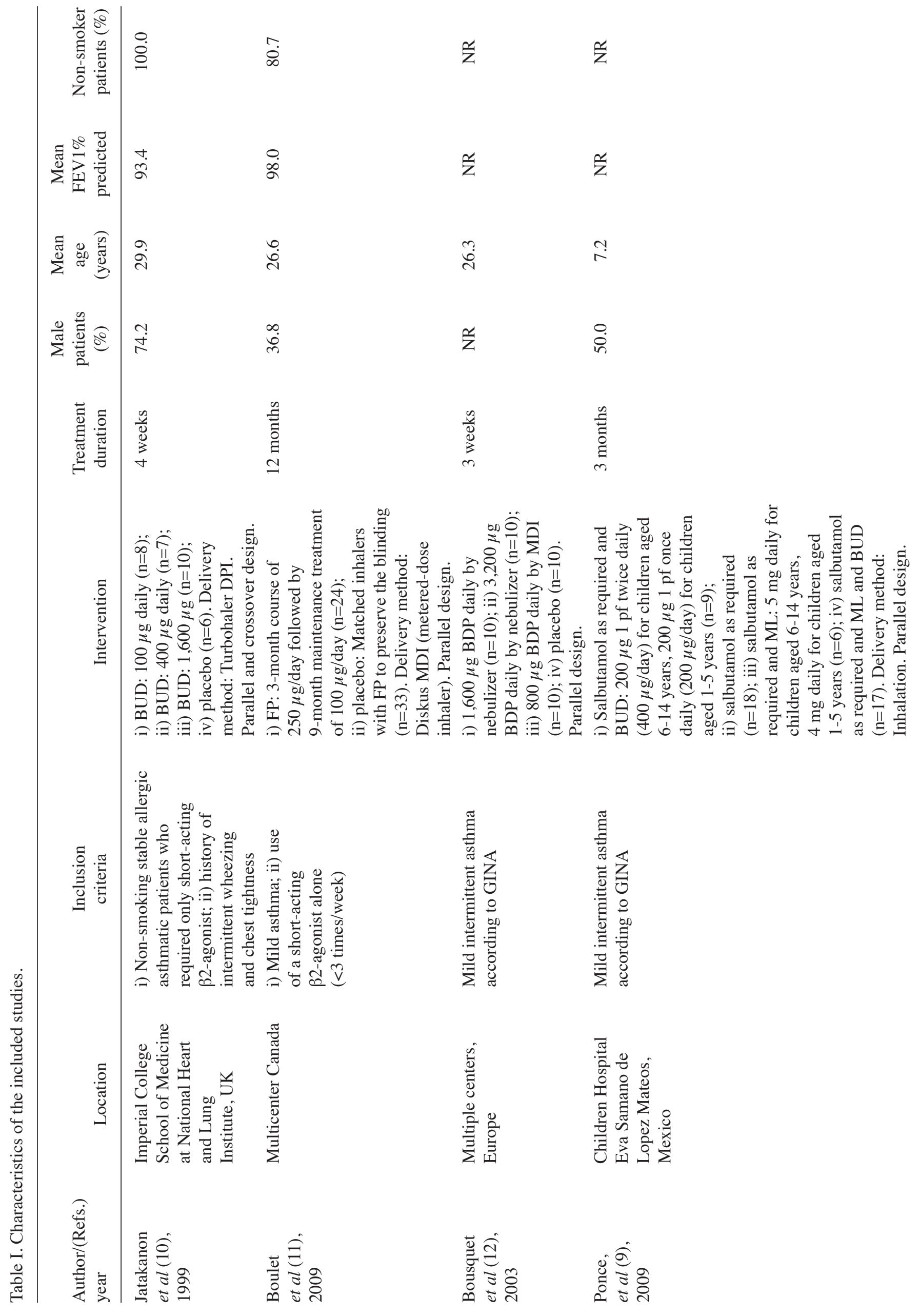




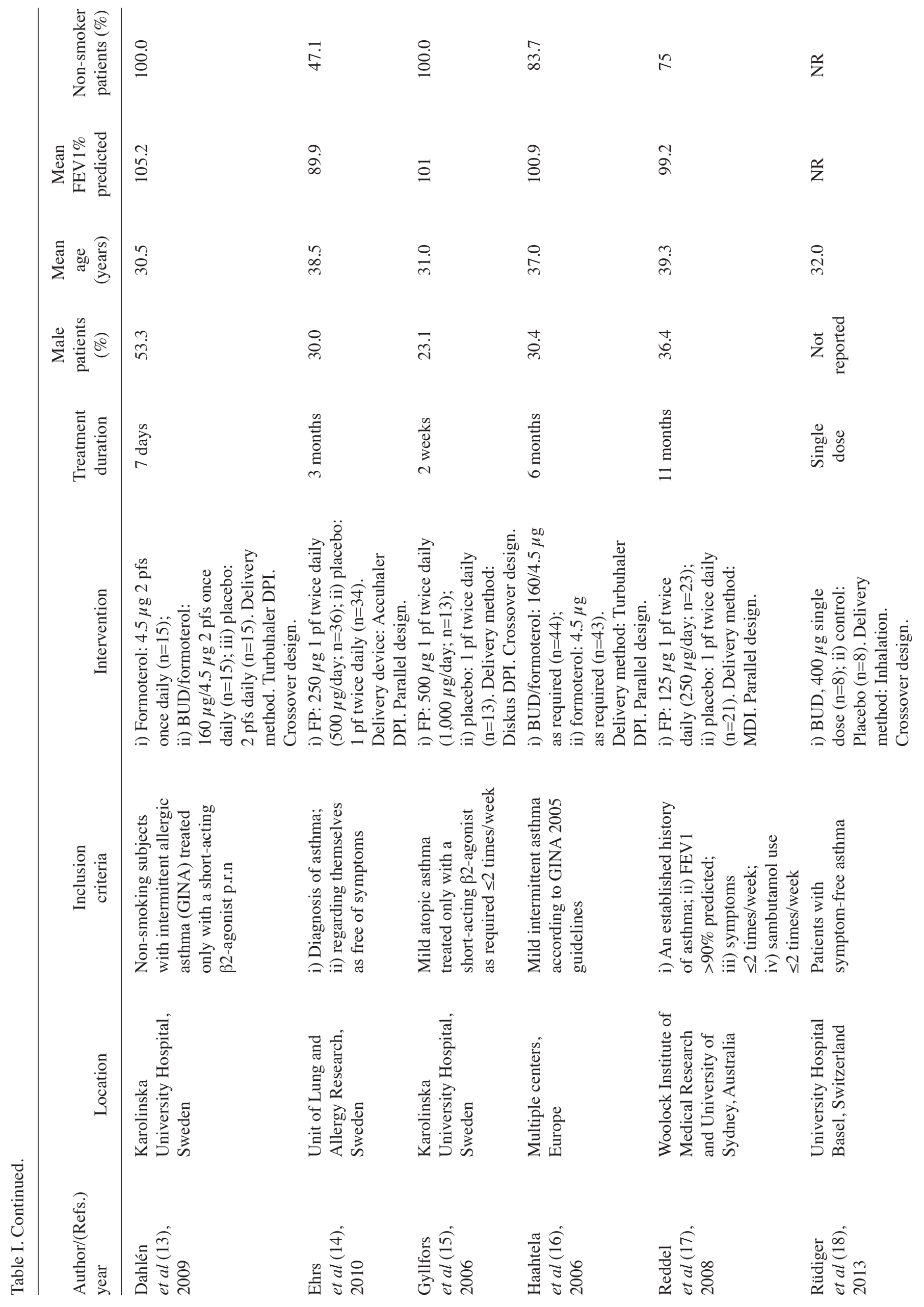




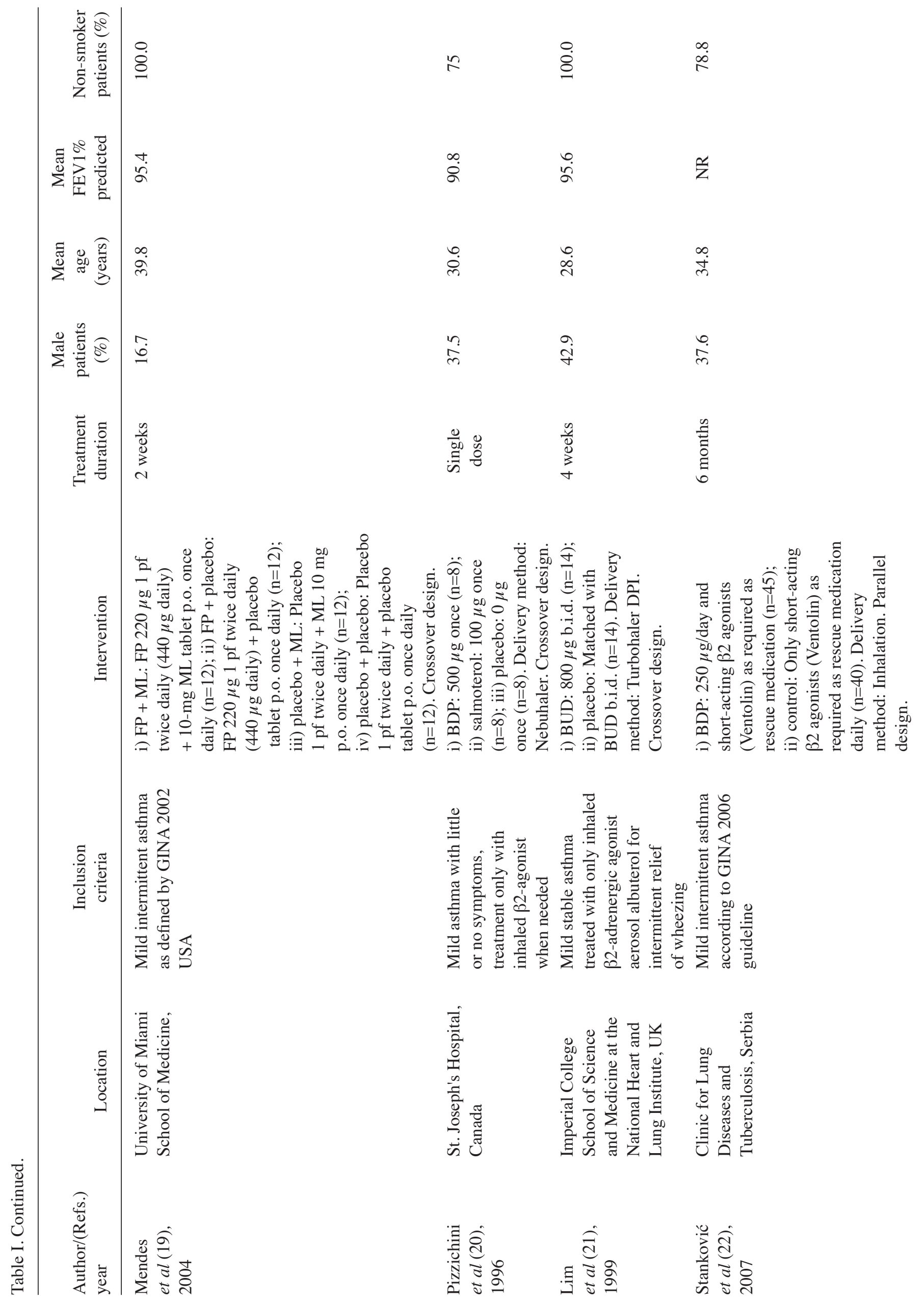




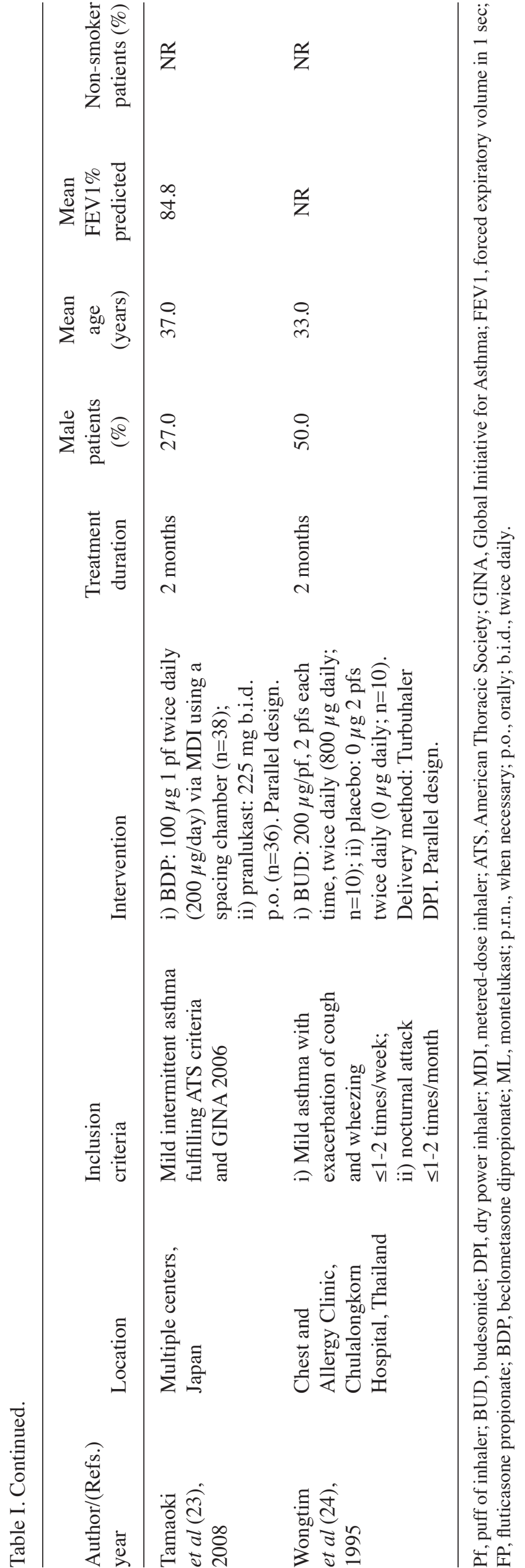

may derive from the inappropriate trial design of the study by Stanković et al (22), and the different population of patients may also have caused heterogeneity.

AHR. With treatment of ICS for 1 month, 2-6 months or 1 year, the AHR (indicated as log transformed PC20FEV1) was attenuated compared with placebo $(10,11,13,15,21,22,24)$ ( $\leq 1$ month, 4 studies; SMD, 0.76; 95\% CI, 0.35 to $1.17 ; \mathrm{I}^{2}=28 \%$ vs. 2-6 months, 2 studies; SMD, 0.84; 95\% CI, 0.44 to 1.24 ; $\mathrm{I}^{2}=0 \%$ vs. 1 year, 1 study; SMD, $1.41 ; 95 \% \mathrm{CI}, 0.6$ to 2.22 ; Fig. 4), and the overall improvement effect of ICS on AHR was also significant when compared with the placebo (7 studies; SMD, 0.87; 95\% CI, 0.60 to $1.14 ; \mathrm{I}^{2}=3 \%$; Fig. 4). All results were from adults as there was no AHR outcome assessed in the study investigating children.

\section{Airway inflammation}

Sputum eosinophils. Notably, 1 month of ICS treatment reduced the sputum eosinophil percentage compared with placebo, whereas 1 -year treatment could not $(10,11,21)$ (1 month, 2 studies; WMD, $-3.64 \%$; 95\% CI, -6.29 to $-1.00 \%$, $\mathrm{I}^{2}=0 \%$ vs. 1 year, 1 study; WMD, $-0.7 \%$; $95 \% \mathrm{CI},-1.91$ to $0.51 \%$; Fig. $5 \mathrm{~A}$ ). It was shown in one study that single dose ICS could not change it (20). Overall analysis showed no significant sputum eosinophil percentage change with ICS treatment vs. placebo (3 studies; WMD, $-2.07 \%$; $95 \%$ CI, -4.52 to $0.37 \% ; I^{2}=56 \%$; Fig. $\left.5 \mathrm{~A}\right)$. The heterogeneity $\left(\mathrm{I}^{2}=56 \%\right)$ of this meta-analysis may be associated with the distinct treatment duration of the 3 studies and the small sample size of these studies.

Only one study compared the influence of ICS on sputum eosinophil percentage with LTRA, and showed that ICS decreased sputum eosinophil percentage with no statistical significance (23) (WMD, -6\%; 95\% CI, -12.38 to $0.38 \%$ ). All results of airway inflammation were from adults, and there was no related outcomes in the study evaluating children.

FeNO. ICS treatment within 1 month reduced FeNO levels compared with placebo $(10,13,21)$ ( 3 studies; WMD, $-17.21 \mathrm{ppb}$; 95\% CI, -24.08 to $-10.35 \mathrm{ppb} ; \mathrm{I}^{2}=0 \%$; Fig. 5B), and after 3, 6 months or 1 year of treatment, similar results were found [3 months, one study (14); WMD, -7.7 ppb; 95\% CI, -13.45 to $-1.95 \mathrm{ppb}$; vs. 6 months, one study (16); WMD, $-15.5 \mathrm{ppb}$; 95\% CI, -23.5 to -7.5 ppb vs. 1 year, one study (17); WMD, $-12.68 \mathrm{ppb} ; 95 \% \mathrm{CI},-19.17$ to $-6.19 \mathrm{ppb}$. Overall analysis showed an apparent reduced FeNO level (6 studies; WMD, $-12.57 \mathrm{ppb} ; 95 \% \mathrm{CI},-15.88$ to $-9.25 \mathrm{ppb} ; \mathrm{I}^{2}=7 \%$; Fig. 5B).

Symptom control. When the duration of ICS treatment was no more than 1 month, the effect of ICS on symptom control (indicated as symptom score change) was not significant compared with placebo $(10,13)$ (2 studies; SMD, -0.29 ; 95\% CI, -0.79 to $0.22 ; \mathrm{I}^{2}=11 \%$; Fig. $\left.6 \mathrm{~A}\right)$. Similarly, after $2-6$ months or 1 year of treatment the effect of ICS on symptom control was not significant [2-6 months, 3 studies (16,22,24); SMD, -0.25; 95\% CI, -0.7 to $0.2 ; \mathrm{I}^{2}=52 \%$; and 1 year, one study (11) SMD, -0.49 ; 95\% CI, -1.21 to 0.24 ; Fig. 6A]. The overall effect of ICS on symptom score change was not significant (6 studies; SMD, $-0.26 ; 95 \%$ CI, -0.52 to $0 ; \mathrm{I}^{2}=15 \%$; Fig. $6 \mathrm{~A}$ ). However, ICS was able to reduce the frequency of rescue inhaler use after 


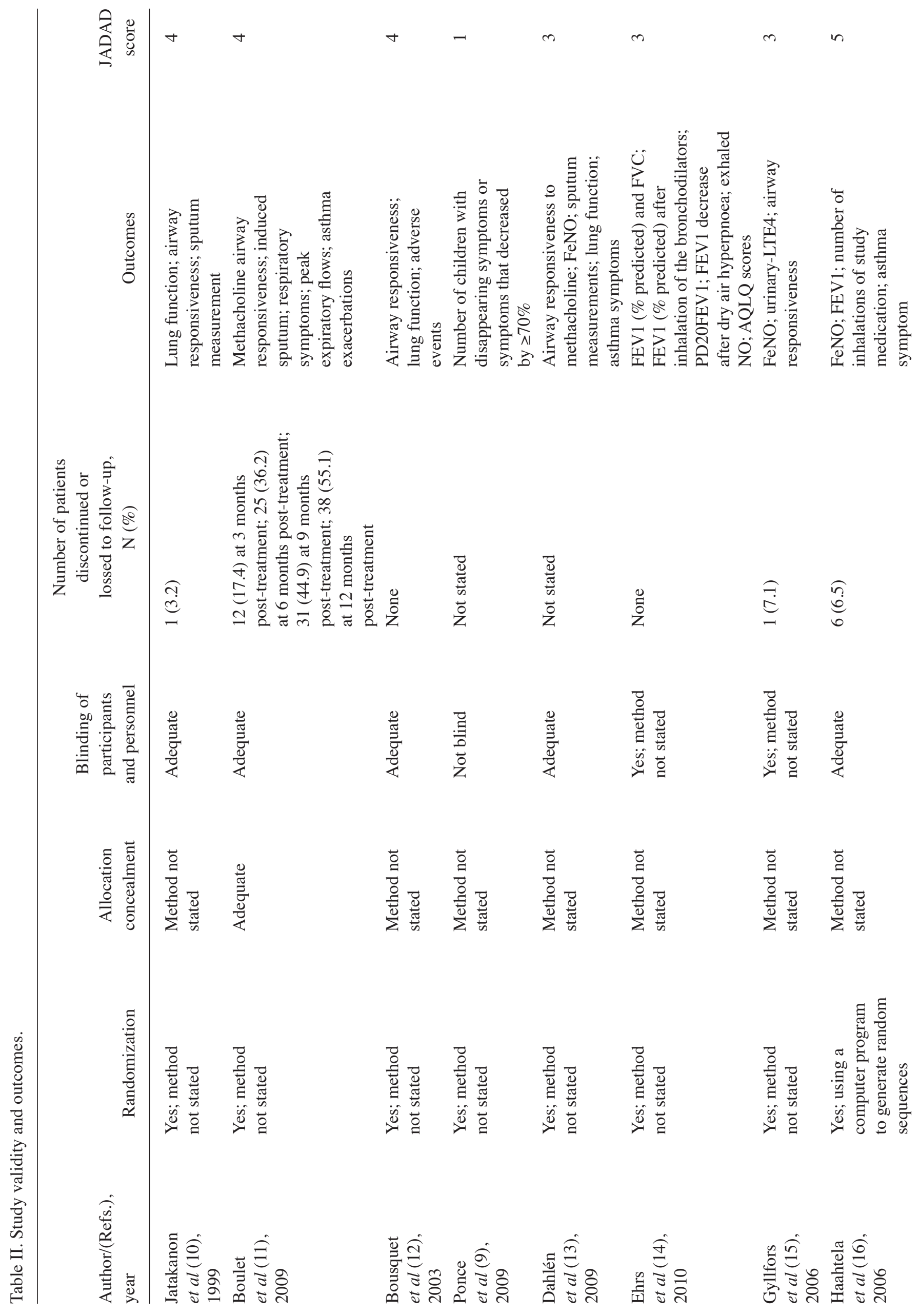




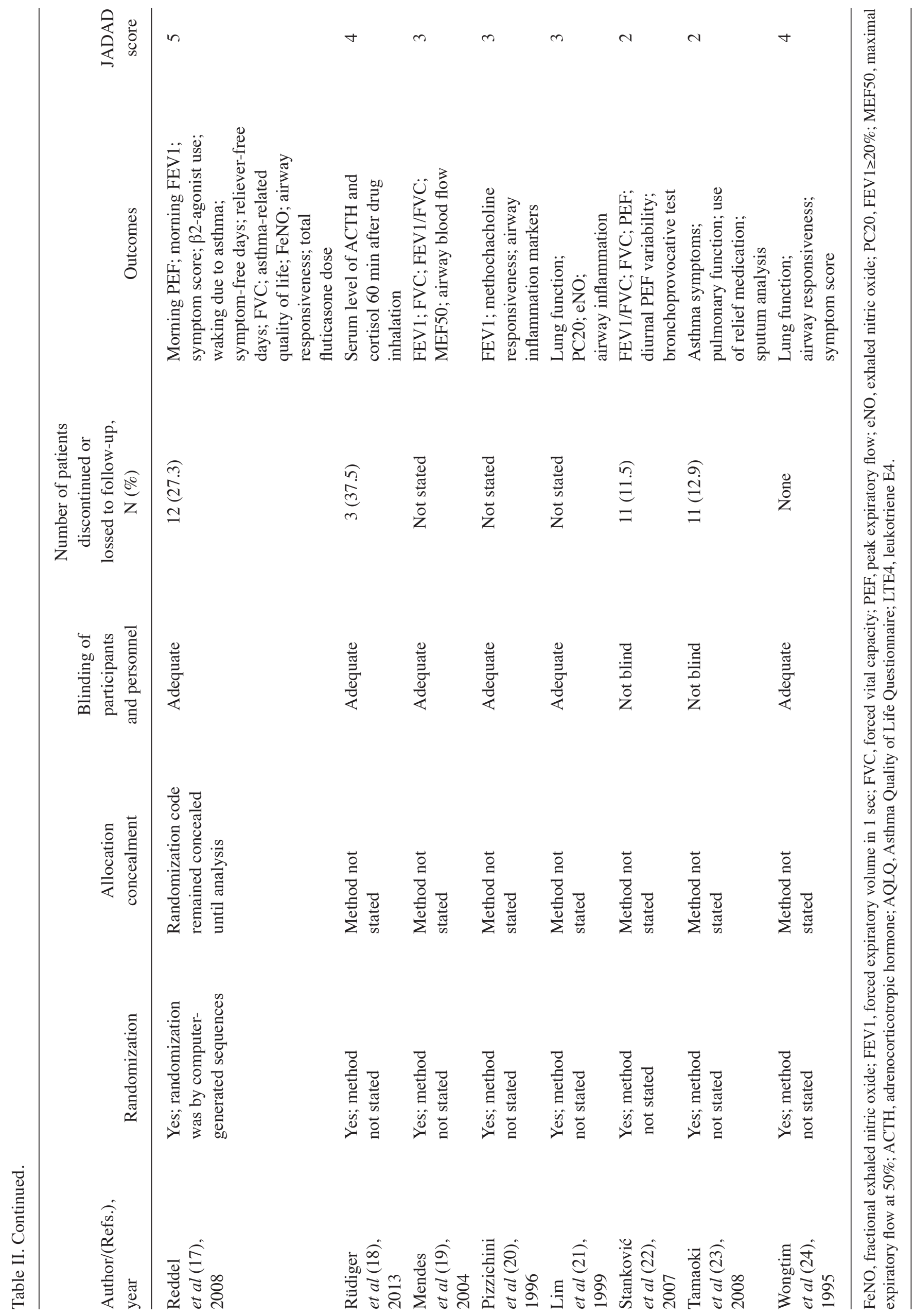




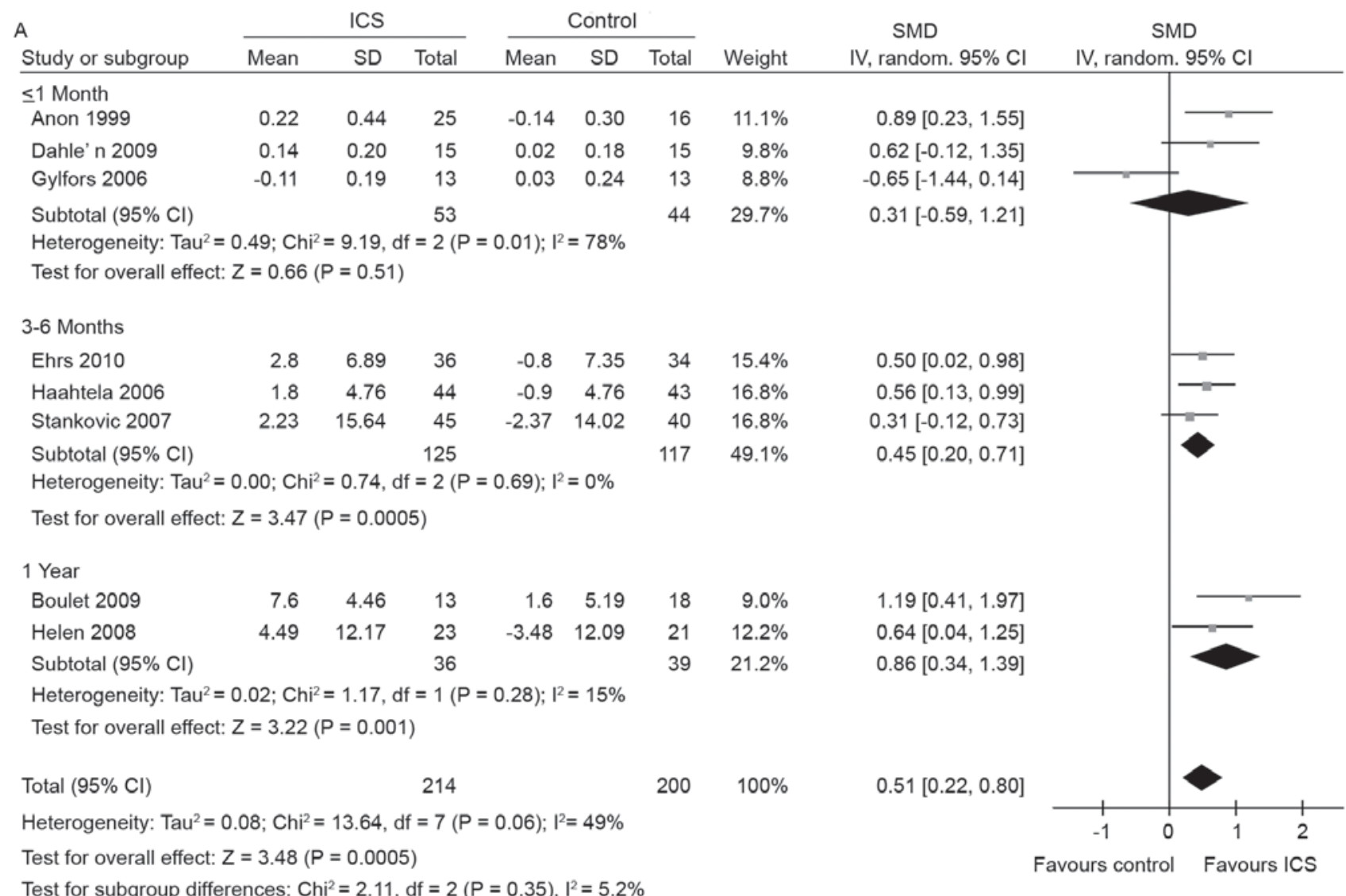

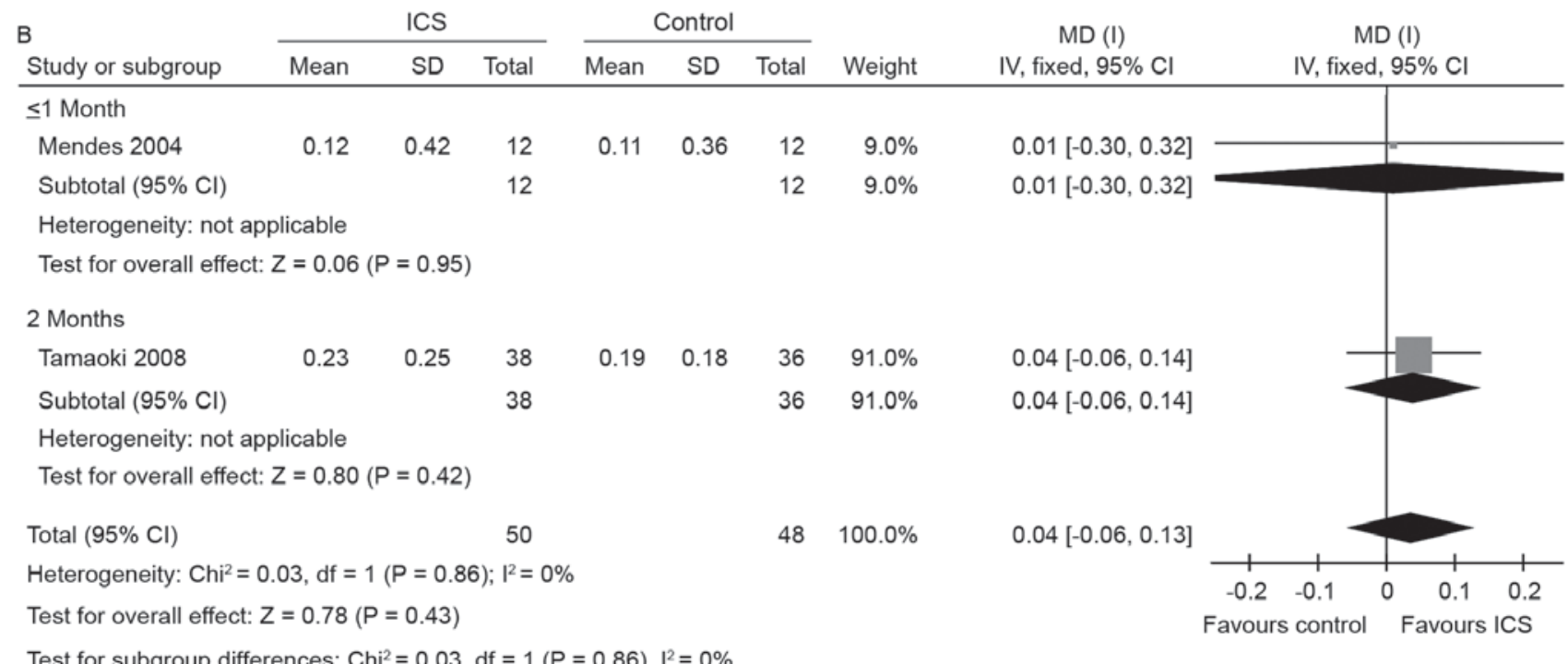

Figure 2. ICS improves FEV1 but has no advantage over LTRA. (A) Effect of ICS vs. placebo on FEV1 change. (B) Effect of ICS vs. LTRA on FEV1 change. ICS, inhaled corticosteroid; FEV1, forced expiratory volume in $1 \mathrm{sec}$; SD, standard deviation; SMD, standardized mean difference; MD, mean difference; CI, confidence interval; LTRA, leukotriene receptor antagonists.

1-2 months of treatment when compared with placebo $(10,24)$ (2 studies; SMD, $-1.34 ; 95 \%$ CI, -1.92 to -0.76 ; $\mathrm{I}^{2}=0 \%$; Fig. 6B).

There was only one study (9) concerned with the symptom control of children with mild intermittent asthma, which indicated that 3 months of treatment with ICS significantly increased the number of children without asthma symptoms (RR, 8; 95\% CI, 1.04 to 61.52) compared with placebo. When compared with LTRA, low dose ICS (3 months) was not found to significantly influence symptom control (23) (SMD, 0.44; 95\% CI, -0.02 to 0.9 ) in adult patients; however, the number of children without asthma symptoms significantly increased over the same period of low dose ICS (9) (RR, 2.67; 95\% CI, 0.39 to 18.42 ).

Other parameters. Some studies also assessed the safety of ICS in addition to its effectiveness. However, there was an 


\begin{tabular}{|c|c|c|c|c|c|c|c|c|c|}
\hline \multirow{2}{*}{$\begin{array}{l}\text { A } \\
\text { Study or subgroup }\end{array}$} & \multicolumn{3}{|c|}{ ICS } & \multicolumn{3}{|c|}{ Control } & \multirow{2}{*}{\multicolumn{2}{|c|}{$\begin{array}{l}\mathrm{MD} \\
\mathrm{IV}, \text { random, } 95 \% \mathrm{Cl}\end{array}$}} & \multirow{2}{*}{$\begin{array}{c}\mathrm{MD} \\
\mathrm{IV}, \text { random, } 95 \% \mathrm{Cl}\end{array}$} \\
\hline & Mean & SD & Total & Mean & SD & Total & & & \\
\hline \multicolumn{10}{|l|}{1 Month } \\
\hline Anon 1999 & -2.52 & 5.05 & 25 & 2.14 & 7.76 & 16 & $16.7 \%$ & $-4.66[-8.95,-0.37]$ & \\
\hline SAM 1999 & 2.1 & 1.53 & 14 & 3.9 & 2.99 & 14 & $36.3 \%$ & $-1.80[-3.56,-0.04]$ & \\
\hline Subtotal $(95 \% \mathrm{Cl})$ & & & 39 & & & 30 & $52.9 \%$ & $-2.54[-4.99,-0.08]$ & \\
\hline \multicolumn{10}{|c|}{ Heterogeneity: $\operatorname{Tau}^{2}=1.30 ; \mathrm{Chi}^{2}=1.46, \mathrm{df}=1(\mathrm{P}=0.23) ; \mathrm{I}^{2}=32 \%$} \\
\hline \multicolumn{10}{|c|}{ Test for overall effect: $Z=2.03(P=0.04)$} \\
\hline \multicolumn{10}{|l|}{6 Months } \\
\hline Stankovic 2007 & -4.09 & 0.90 & 45 & 0.48 & 0.73 & 40 & $47.1 \%$ & $-4.57[-4.92,-4.22]$ & \\
\hline Subtotal $(95 \% \mathrm{Cl})$ & & & 45 & & & 40 & $47.1 \%$ & $-4.57[-4.92,-4.22]$ & \\
\hline \multicolumn{10}{|c|}{ Heterogeneity: not applicable } \\
\hline \multicolumn{10}{|c|}{ Test for overall effect: $Z=25.84(P<0.00001)$} \\
\hline Total $(95 \% \mathrm{Cl})$ & & & 84 & & & 70 & $100.0 \%$ & $-3.58[-5.75,-1.41]$ & \\
\hline \multicolumn{9}{|c|}{ Heterogeneity: $\mathrm{Tau}^{2}=2.57 ; \mathrm{Chi}^{2}=9.15, \mathrm{df}=2(\mathrm{P}=0.01) ; \mathrm{I}^{2}=78 \%$} & $10 \quad-5$ \\
\hline \multicolumn{10}{|c|}{ Test for overall effect: $Z=3.24(P=0.001)$} \\
\hline
\end{tabular}

Test for subgroup differences: $\mathrm{Chi}^{2}=2.59, \mathrm{df}=1(\mathrm{P}=0.11), \mathrm{I}^{2}=61.4 \%$

\begin{tabular}{|c|c|c|c|c|c|c|c|c|c|}
\hline \multirow{2}{*}{$\begin{array}{l}\text { B } \\
\text { Study or subgroup }\end{array}$} & \multicolumn{3}{|c|}{ ICS } & \multicolumn{3}{|c|}{ Control } & \multirow{2}{*}{\multicolumn{2}{|c|}{$\begin{array}{l}\mathrm{MD} \\
\mathrm{IV} \text {, random, } 95 \% \mathrm{Cl}\end{array}$}} & \multirow{2}{*}{$\begin{array}{c}\mathrm{MD} \\
\mathrm{IV}, \text { random, } 95 \% \mathrm{CI}\end{array}$} \\
\hline & Mean & SD & Total & Mean & SD & Total & & & \\
\hline \multicolumn{10}{|l|}{6 Months } \\
\hline Stankovic 2007 & -0.2 & 3.78 & 45 & -2.9 & 4.19 & 40 & $56.5 \%$ & $2.70[0.99,4.41]$ & \\
\hline Subtotal $(95 \% \mathrm{Cl})$ & & & 45 & & & 40 & $56.5 \%$ & $2.70[0.99,4.41]$ & \\
\hline \multicolumn{10}{|c|}{ Heterogeneity: not applicable } \\
\hline \multicolumn{10}{|c|}{ Test for overall effect: $Z=3.10(P=0.002)$} \\
\hline \multicolumn{10}{|l|}{1 Year } \\
\hline Boulet 2009 & 1.1 & 3.05 & 13 & 1.3 & 4.50 & 18 & $43.5 \%$ & $-0.20[-2.86,2.46]$ & \\
\hline Subtotal $(95 \% \mathrm{Cl})$ & & & 13 & & & 18 & $43.5 \%$ & $-0.20[-2.86,2.46]$ & \\
\hline \multicolumn{10}{|c|}{ Heterogeneity: not applicable } \\
\hline \multicolumn{10}{|c|}{ Test for overall effect: $Z=0.15(P=0.88)$} \\
\hline Total $(95 \% \mathrm{Cl})$ & & & 58 & & & 58 & $100.0 \%$ & $1.44[-1.38,4.26]$ & \\
\hline \multicolumn{9}{|c|}{ Heterogeneity: $\mathrm{Tau}^{2}=2.90 ; \mathrm{Chi}^{2}=3.23, \mathrm{df}=1(P=0.07) ; \mathrm{I}^{2}=69 \%$} & $-4 \quad-2$ \\
\hline \multicolumn{10}{|c|}{ Test for overall effect: $Z=1.00(P=0.32)$} \\
\hline
\end{tabular}

Test for subgroup differences: $\mathrm{Chi}^{2}=3.23, \mathrm{df}=1(\mathrm{P}=0.07), \mathrm{I}^{2}=69.0 \%$

Figure 3. ICS improves PEF variability change but not FEV1/FVC. (A) Effect of ICS vs. placebo on PEF variability change. (B) Effect of ICS vs. placebo on FEV1/FVC change. ICS, inhaled corticosteroid; PEF, peak expiratory flow; FEV1, forced expiratory volume in 1 sec; FVC, forced vital capacity; SD, standard deviation; MD, mean difference; CI, confidence interval.

insufficient number of related. Only one study assessed the effect of ICS on the hypothamo-pituitary-adrenocortical axis, in which Rüdiger et al (18) found that single low dose ICS did not influence this endocrine axis. Bousquet et al (12) also claimed that 3 weeks of high dose ICS did not increase the number of patients experiencing adverse events (RR, 1.00; 95\% CI, 0.42 to 2.4). These studies indicate that ICS treatment may be safe over a short period, whereas the safety of long-term use in patients with mild intermittent asthma remains unclear.

\section{Discussion}

The present systemic review attempted to assess the effects of ICS compared with placebo or LTRA on lung function,
AHR, airway inflammation, symptom control and its adverse effects in patients with mild intermittent asthma. The findings demonstrated that, compared with a placebo, ICS improved lung function and reduced AHR and airway inflammation in adult patients. However, symptom control was unchanged, and ICS had no advantage over LTRA for improving lung function and attenuating airway inflammation. In children with mild intermittent asthma, ICS had a positive effect on symptom control and was superior to LTRA in terms of symptom control.

Previous findings have revealed that ICS treatment results in improved lung function, diminished AHR, fewer symptoms of asthma and fewer episodes of uncontrolled asthma compared with as needed SABA alone (25), and studies 


\begin{tabular}{|c|c|c|c|c|c|c|c|c|c|}
\hline \multirow[b]{2}{*}{ Study or subgroup } & \multicolumn{3}{|c|}{ ICS } & \multicolumn{3}{|c|}{ Control } & \multirow[b]{2}{*}{ Weight } & \multirow{2}{*}{$\begin{array}{c}\text { SMD } \\
\text { IV, fixed, } 95 \% \mathrm{Cl}\end{array}$} & \multirow{2}{*}{$\begin{array}{c}\text { SMD } \\
\text { IV, fixed, } 95 \% \mathrm{Cl}\end{array}$} \\
\hline & Mean & SD & Total & Mean & SD & Total & & & \\
\hline \multicolumn{10}{|l|}{$\leq 1$ Month } \\
\hline Anon 1999 & 0.23 & 3.59 & 15 & -0.23 & 1.09 & 6 & $8.1 \%$ & $0.14[-0.80,1.09]$ & \\
\hline Dahle' n 2009 & 0.54 & 1.07 & 15 & -0.19 & 1.66 & 15 & $13.8 \%$ & $0.51[-0.22,1.24]$ & \\
\hline Gylfors 2006 & 0.41 & 0.43 & 13 & 0.02 & 0.32 & 13 & $10.8 \%$ & $1.00[0.17,1.82]$ & \\
\hline SAM 1999 & 0.62 & 0.40 & 14 & 0.07 & 0.40 & 14 & $10.6 \%$ & $1.32[0.49,2.15]$ & \\
\hline Subtotal $(95 \% \mathrm{Cl})$ & & & 57 & & & 48 & $43.3 \%$ & $0.76[0.35,1.17]$ & \\
\hline \multicolumn{10}{|c|}{ Heterogeneity: $\mathrm{Chi}^{2}=4.15, \mathrm{df}=3(\mathrm{P}=0.25) ; \mathrm{I}^{2}=28 \%$} \\
\hline \multicolumn{10}{|c|}{ Test for overall effect: $Z=3.63(P=0.0003)$} \\
\hline \multicolumn{10}{|l|}{ 2-6 Months } \\
\hline Stankovic 2007 & 0.75 & 1.42 & 45 & -0.52 & 1.62 & 40 & $37.0 \%$ & $0.83[0.38,1.27]$ & \\
\hline Wongtim 1995 & 0.6 & 0.63 & 10 & 0.004 & 0.63 & 10 & $8.4 \%$ & $0.90[-0.03,1.83]$ & \\
\hline Subtotal $(95 \% \mathrm{Cl})$ & & & 55 & & & 50 & $45.4 \%$ & $0.84[0.44,1.24]$ & \\
\hline \multicolumn{10}{|c|}{ Heterogeneity: $\mathrm{Chi}^{2}=0.02, \mathrm{df}=1(\mathrm{P}=0.89) ; \mathrm{I}^{2}=0 \%$} \\
\hline \multicolumn{10}{|c|}{ Test for overall effect: $Z=4.10(P<0.0001)$} \\
\hline \multicolumn{10}{|l|}{1 Year } \\
\hline Boulet 2009 & 3.72 & 1.97 & 13 & 1.19 & 1.58 & 18 & $11.2 \%$ & $1.41[0.60,2.22]$ & \\
\hline Subtotal $(95 \% \mathrm{Cl})$ & & & 13 & & & 18 & $11.2 \%$ & $1.41[0.60,2.22]$ & \\
\hline \multicolumn{10}{|c|}{$\begin{array}{l}\text { Heterogeneity: not applicable } \\
\text { Test for overall effect: } Z=3.43(P=0.0006)\end{array}$} \\
\hline Total $(95 \% \mathrm{Cl})$ & & & 125 & & & 116 & $100.0 \%$ & $0.87[0.60,1.14]$ & \\
\hline \multicolumn{9}{|c|}{ Heterogeneity: $\mathrm{Chi}^{2}=6.18, \mathrm{df}=6(\mathrm{P}=0.40) ; \mathrm{I}^{2}=3 \%$} & 0 \\
\hline
\end{tabular}

Figure 4. ICS treatment attenuates airway hyper-responsiveness, when compared with placebo treatment. ICS, inhaled corticosteroid; SD, standard deviation; SMD, standardized mean difference; CI, confidence interval.

involving mild persistent asthma have indicated the necessity of ICS therapy in these patients (4). However, studies associated with mild intermittent asthma are lacking, and, due to the potential long-term side effects of ICS (such as accelerated bone loss), experts still regard SABA as the first-line treatment for patients with intermittent asthma $(2,26)$. A recent study focused on airway inflammation in mild intermittent steroid-naïve asthmatic patients found that many patients still exhibited persistent airway inflammation, which could result in airway remodeling $(4,7)$, and nearly $6 \%$ of these patients required hospitalization or attended the emergency department annually (27). The effect of ICS on bone mineral density seemed to be slight and thus remains controversial (28). Therefore, at least in some patients with mild intermittent asthma, ICS should be considered.

The present results showed that a longer duration of ICS treatment induces a superior improvement in lung function and the alleviation of AHR; however, the effect of attenuated airway inflammation reduces as the treatment duration increases. A previous study focused on patients with mild persistent asthma, lung function and observed an improvement during the first year (29), which was consistent with our study concerning patients with mild intermittent asthma. However, the improvement was decreased after 1 year in patients with persistent asthma (30), and AHR was only found to be increasingly improved during the first 3 months in patients with mild persistent asthma (31); consistent with our study, AHR was increasingly improved during the first year, implying the effect of ICS on improvement of AHR is more durable in patients with intermittent asthma.
In our study, both sputum eosinophil percentages and FeNO levels were used as markers for airway inflammation, but the FeNO change was more obvious. In the majority of asthmatic patients, the correlation between sputum eosinophil and FeNO is well established, except in patients with severe asthma (32), and the major site of synthesis of NO is airway epithelial cells (32). Based on our results, we conclude that in patients with intermittent asthma, the airway epithelial cells are more sensitive to ICS treatment than eosinophils.

Side effects of ICS are always a concern. Short-term ICS use is believed to be safe $(12,18)$; however, longer treatment with high dose ICS may decrease bone mineral density and increase the risk of osteoporosis or fracture in patients with persistent asthma, but the effect of low dose ICS on bone mineral density and risk of osteoporosis or fracture was slight (28). Dysphonia or oral candidiasis may also develop, but it could almost be prevented by rinsing the mouth after ICS use (33). Therefore, low dose ICS may be safe for patients with mild asthma, including those with intermittent asthma.

There are a number of limitations to the present systemic review. Firstly, the treatment duration of all the studies included may not sufficient. This limitation prevents us from identifying more positive and negative effects of ICS on patients with mild intermittent and confuses the evaluation of the balance of ICS benefits and risks. Secondly, the number of included studies is too small, thus publication bias may exist, and the conclusion from the review may not be able to applicable to a larger population. Thirdly, some of the included studies were not high quality trials, which may result in an increased risk of bias. 


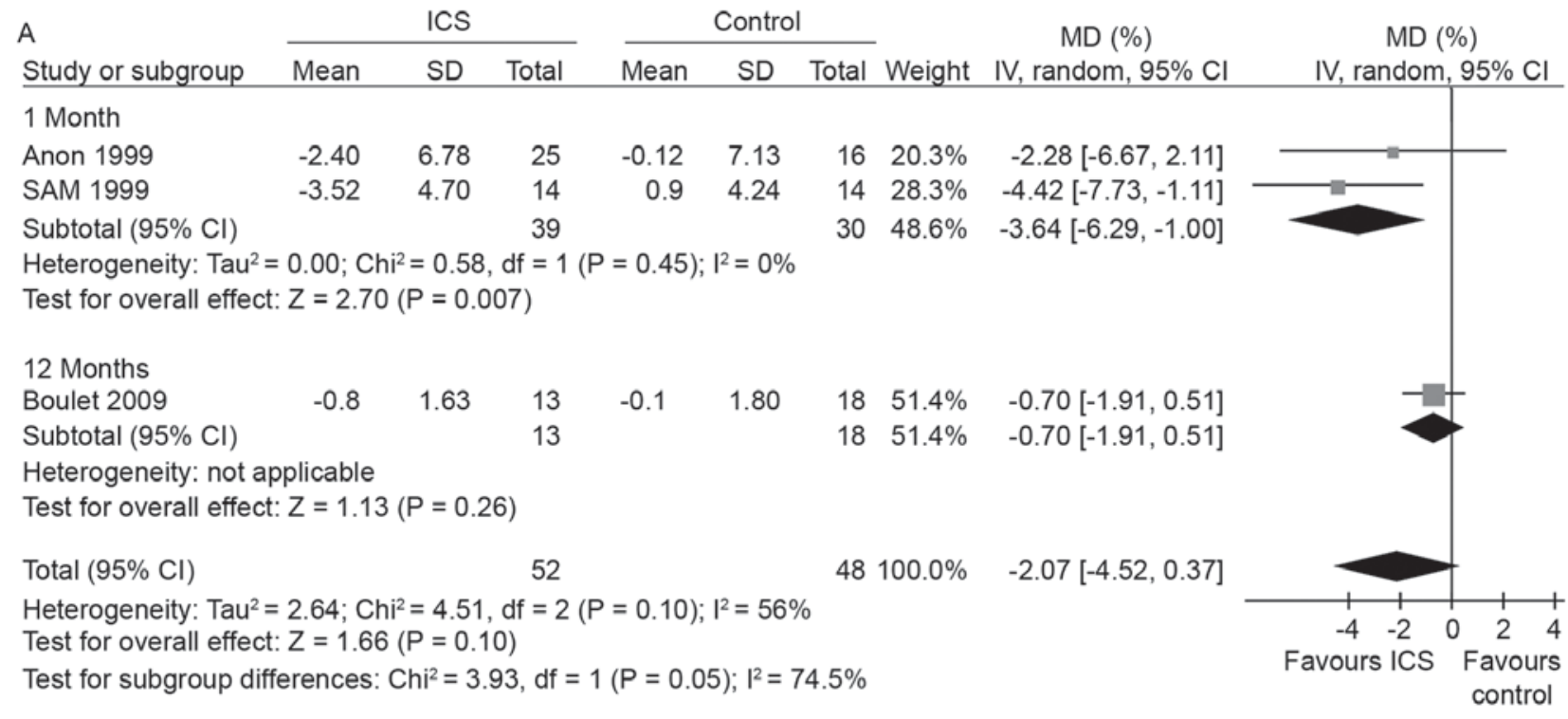

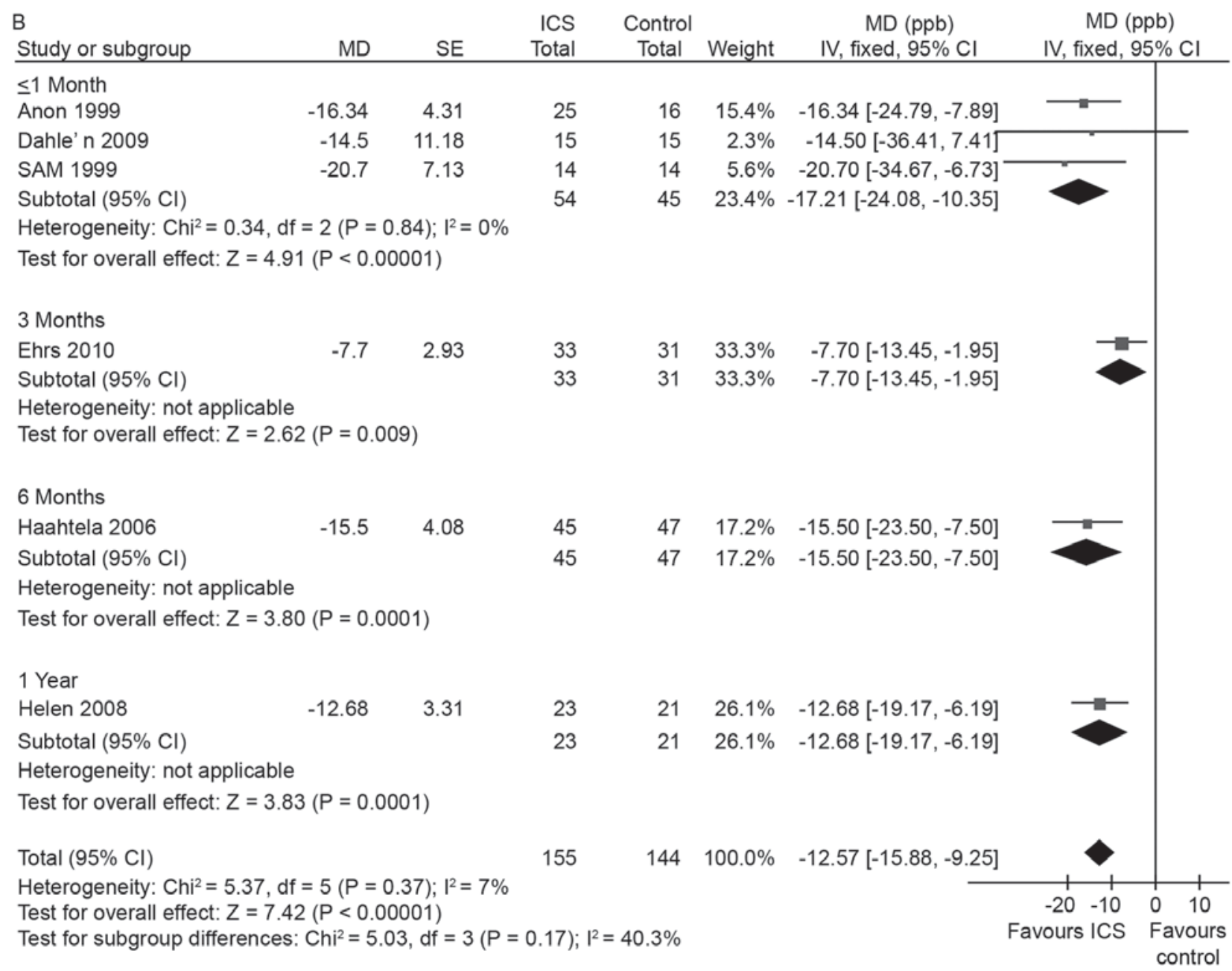

Figure 5. Airway inflammation reduces with ICS treatment. (A) Effect of ICS vs. placebo on sputum eosinophil change. (B) Effect of ICS vs. placebo on FeNO change. ICS, inhaled corticosteroid; SD, standard deviation; MD, mean difference; CI, confidence interval; FeNO, fractional exhaled nitric oxide.

In conclusion, the present systemic review demonstrates that ICS may improve lung function, alleviate airway inflammation and AHR, but cannot ameliorate symptom control in adult patients with mild intermittent asthma, and has no advantage over LTRA on these effects. On the contrary, children with mild intermittent asthma treated with ICS seemingly have a better control of asthma symptoms vs. placebo or LTRA treatment. Our findings indicate that ICS may be an effective and safe therapy for patients with mild intermittent showing signs of progression or exacerbation, and LTRA should be an alternate choice for adult patients to improve lung function and reduce airway inflammation. As for child patients, ICS seems 


\begin{tabular}{|c|c|c|c|c|c|c|c|c|c|c|}
\hline \multirow{2}{*}{$\begin{array}{l}\text { A } \\
\text { Study or subgroup }\end{array}$} & \multicolumn{3}{|c|}{ ICS } & \multicolumn{3}{|c|}{ Control } & \multirow[b]{2}{*}{ Weight } & \multirow{2}{*}{$\begin{array}{c}\text { SMD } \\
\mathrm{IV}, \text { random, } 95 \% \mathrm{Cl}\end{array}$} & \multirow{2}{*}{\multicolumn{2}{|c|}{$\begin{array}{c}\text { SMD } \\
\text { IV, random, } 95 \% \mathrm{Cl}\end{array}$}} \\
\hline & Mean & SD & Total & Mean & SD & Total & & & & \\
\hline \multicolumn{11}{|l|}{$\leq 1$ Month } \\
\hline Anon 1999 & -0.40 & 0.92 & 25 & 0 & 0.32 & 16 & $14.3 \%$ & $-0.52[-1.16,0.12]$ & & \\
\hline Dahle' n 2009 & 0.1 & 0.32 & 15 & 0.1 & 0.32 & 15 & $11.7 \%$ & $0.00[-0.72,0.72]$ & & \\
\hline Subtotal $(95 \% \mathrm{Cl})$ & & & 40 & & & 31 & $26.0 \%$ & $-0.29[-0.79,0.22]$ & & \\
\hline \multicolumn{11}{|c|}{ Heterogeneity: $\mathrm{Tau}^{2}=0.01 ; \mathrm{Chi}^{2}=1.12, \mathrm{df}=1(\mathrm{P}=0.29) ; \mathrm{I}^{2}=11 \%$} \\
\hline \multicolumn{11}{|c|}{ Test for overall effect: $Z=1.11(P=0.27)$} \\
\hline \multicolumn{11}{|l|}{ 2-6 Months } \\
\hline Haahtela 2006 & -0.24 & 0.79 & 44 & -0.31 & 0.92 & 43 & $28.1 \%$ & $0.08[-0.34,0.50]$ & & \\
\hline Stankovic 2007 & -0.33 & 2.01 & 45 & 0.16 & 0.73 & 40 & $27.3 \%$ & $-0.31[-0.74,0.12]$ & & \\
\hline Wongtim 1995 & -0.50 & 0.54 & 10 & 0 & 0.54 & 10 & $7.2 \%$ & $-0.90[-1.83,0.03]$ & & \\
\hline Subtotal $(95 \% \mathrm{Cl})$ & & & 99 & & & 93 & $62.6 \%$ & $-0.25[-0.70,0.20]$ & & \\
\hline \multicolumn{11}{|c|}{ Heterogeneity: $\mathrm{Tau}^{2}=0.08 ; \mathrm{Chi}^{2}=4.15, \mathrm{df}=2(P=0.13) ; \mathrm{I}^{2}=52 \%$} \\
\hline \multicolumn{11}{|c|}{ Test for overall effect: $Z=1.09(P=0.27)$} \\
\hline \multicolumn{11}{|l|}{1 Year } \\
\hline Boulet 2009 & 0.4 & 0.8 & 13 & 0.8 & 0.8 & 18 & $11.4 \%$ & $-0.49[-1.21,0.24]$ & & \\
\hline Subtotal $(95 \% \mathrm{Cl})$ & & & 13 & & & 18 & $11.4 \%$ & $-0.49[-1.21,0.24]$ & & \\
\hline \multicolumn{11}{|c|}{ Heterogeneity: not applicable } \\
\hline \multicolumn{11}{|c|}{ Test for overall effect: $Z=1.32(P=0.19)$} \\
\hline Total $(95 \% \mathrm{Cl})$ & & & 152 & & & 142 & $100.0 \%$ & $-0.26[-0.52,0.00]$ & & \\
\hline \multicolumn{9}{|c|}{ Heterogeneity: $\mathrm{Tau}^{2}=0.02 ; \mathrm{Chi}^{2}=5.89, \mathrm{df}=5(\mathrm{P}=0.32) ; \mathrm{I}^{2}=15 \%$} & -1 & 0 \\
\hline \multicolumn{9}{|c|}{ Test for overall effect: $Z=1.95(P=0.05)$} & Favours ICS & $\begin{array}{l}\text { Favours } \\
\text { control }\end{array}$ \\
\hline
\end{tabular}

\begin{tabular}{|c|c|c|c|c|c|c|c|c|c|}
\hline \multirow{2}{*}{$\begin{array}{l}\text { B } \\
\text { Study or subgroup }\end{array}$} & \multicolumn{3}{|c|}{ ICS } & \multicolumn{3}{|c|}{ Control } & \multirow[b]{2}{*}{ Weight } & \multirow{2}{*}{$\begin{array}{c}\text { MD (puff/d) } \\
\text { IV, fixed, } 95 \% \mathrm{Cl}\end{array}$} & \multirow{2}{*}{$\begin{array}{c}\text { MD (puff/d) } \\
\text { IV, fixed, } 95 \% \mathrm{Cl}\end{array}$} \\
\hline & Mean & SD & Total & Mean & SD & Total & & & \\
\hline Anon 1999 & -0.69 & 0.96 & 15 & 0.6 & 0.49 & 6 & $86.9 \%$ & $-1.29[-1.91,-0.66]$ & \\
\hline Wongtim 1995 & -1.49 & 1.83 & 10 & 0.22 & 1.83 & 10 & $13.1 \%$ & $-1.72[-3.32,-0.12]$ & \\
\hline Total $(95 \% \mathrm{Cl})$ & & & 25 & & & 16 & $100.0 \%$ & $-1.34[-1.92,-0.76]$ & $\theta$ \\
\hline \multicolumn{9}{|c|}{ Heterogeneity: $\mathrm{Chi}^{2}=0.24, \mathrm{df}=1(\mathrm{P}=0.62) ; \mathrm{I}^{2}=0 \%$} & 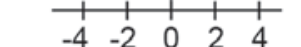 \\
\hline \multicolumn{9}{|c|}{ Test for overall effect: $Z=4.54(P<0.00001)$} & $\begin{array}{c}\text { Favours ICS Favours } \\
\text { control }\end{array}$ \\
\hline
\end{tabular}

Figure 6. Symptom scores do not change with ICS treatment, but rescue inhaler use reduces. (A) Effect of ICS vs. placebo on symptom score change. (B) Effect of ICS on frequency of rescue inhaler use change. ICS, inhaled corticosteroid; SD, standard deviation; SMD, standardized mean difference; MD, mean difference; CI, confidence interval.

to be the superior choice to control symptoms, but should be used with caution, as the evidence remains insufficient.

\section{References}

1. Feng $X$ and Lin $J$ (eds.): An Epidemiology Survey On The Prevalence And Associated Risk Factors Of Asthma Among Adults In China. Peking Union Medical College Press, Beijing, p94, 2014.

2. Global Initiative for Asthma (GINA): From the Global Strategy for Asthma Management and Prevention, 2015. http://www. ginasthma.org. Accessed March 5, 2016.

3. Humbert M, Holgate S, Boulet LP and Bousquet J: Asthma control or severity: That is the question. Allergy 62: 95-101, 2007.

4. Dusser D, Montani D, Chanez P, de Blic J, Delacourt C, Deschildre A, Devillier P, Didier A, Leroyer C, Marguet C, et al: Mild asthma: An expert review on epidemiology, clinical characteristics and treatment recommendations. Allergy 62: 591-604, 2007.

5. Israel E and Drazen JM: Treating mild asthma-when are inhaled steroids indicated? N Engl J Med 331: 737-739, 1994.
6. Van den Toorn LM: Clinical implications of airway inflammation in mild intermittent asthma. Ann Allergy Asthma Immunol 92: 589-594; quiz 595-7, 658, 2004.

7. Pedersen F, Holz O, Kanniess F, Zielen S, Schulze J, Gillissen A, von Berg A, Berdel D, Beier J, Beeh K, et al: Longitudinal measurement of airway inflammation over one year in children and adults with intermittent asthma. BMC Res Notes 7: 925, 2014.

8. Higgins JPT, Deeks JJ and Altman DG: Analysing data and undertaking meta-analyses. In: Cochrane Handbook for Systematic Reviews of Interventions. Higgins JPT and Green S (eds). John Wiley \& Sons, Chichester, UK, pp243-296, 2008.

9. Ponce Castro H, Rodríguez Espino S and Rodríguez Orozco AR: Administration of budesonide (inhaled steroid) to children to control intermittent asthma. Rev Alerg Mex 56: 9-12, 2009 (In Spanish).

10. Jatakanon A, Kharitonov S, Lim S and Barnes PJ: Effect of differing doses of inhaled budesonide on markers of airway inflammation in patients with mild asthma. Thorax 54: 108-114, 1999.

11. Boulet LP, Turcotte H, Prince $P$, Lemière $C$, Olivenstein R, Laprise C, Larivée P, Bégin P and Laviolette M: Benefits of low-dose inhaled fluticasone on airway response and inflammation in mild asthma. Respir Med 103: 1554-1563, 2009. 
12. Bousquet J, Meziane H, Chanez P, Mueser M and Umile A: The response of two different dosages of beclometasone dipropionate suspension for nebulization versus a standard dose of beclometasone dipropionate via a metered-dose inhaler on bronchoprovocation testing in adults with asthma. Respir Med 97 (Suppl B): 11-14, 2003.

13. Dahlén B, Lantz AS, Ihre E, Skedinger M, Henriksson E, Jörgensen L, Ekström T, Dahlén SE and Larsson K: Effect of formoterol with or without budesonide in repeated low-dose allergen challenge. Eur Respir J 33: 747-753, 2009.

14. Ehrs PO, Sundblad BM and Larsson K: Effect of fluticasone on markers of inflammation and quality of life in steroid-naive patients with mild asthma. Clin Respir J 4: 51-58, 2010.

15. Gyllfors P, Dahlén SE, Kumlin M, Larsson K and Dahlén B: Bronchial responsiveness to leukotriene D4 is resistant to inhaled fluticasone propionate. J Allergy Clin Immunol 118: 78-83, 2006.

16. Haahtela T, Tamminen K, Malmberg LP, Zetterström O Karjalainen J, Ylä-Outinen $\mathrm{H}$, Svahn T, Ekström $\mathrm{T}$ and Selroos O: Formoterol as needed with or without budesonide in patients with intermittent asthma and raised NO levels in exhaled air: A SOMA study. Eur Respir J 28: 748-755, 2006.

17. Reddel HK, Belousova EG, Marks GB and Jenkins CR: Does continuous use of inhaled corticosteroids improve outcomes in mild asthma? A double-blind randomised controlled trial. Prim Care Respir J 17: 39-45, 2008.

18. Rüdiger JJ, Gencay M, Yang JQ, Bihl M, Tamm M and Roth M Fast beneficial systemic anti-inflammatory effects of inhaled budesonide and formoterol on circulating lymphocytes in asthma. Respirology 18: 840-847, 2013.

19. Mendes ES, Campos MA, Hurtado A and Wanner A: Effect of montelukast and fluticasone propionate on airway mucosal blood flow in asthma. Am J Respir Crit Care Med 169: 1131-1134, 2004.

20. Pizzichini MM, Kidney JC, Wong BJ, Morris MM,Efthimiadis A Dolovich J and Hargreave FE: Effect of salmeterol compared with beclomethasone on allergen-induced asthmatic and inflammatory responses. Eur Respir J 9: 449-455, 1996.

21. Lim S, Jatakanon A, John M, Gilbey T, O'connor BJ, Chung KF and Barnes PJ: Effect of inhaled budesonide on lung function and airway inflammation. Assessment by various inflammatory markers in mild asthma. Am J Respir Crit Care Med 159: 22-30, 1999.

22. Stanković I, Pejcić T, Milenković B, Jovanović D and Rancić M: Is there any point in a corticosteroid treatment of intermittent asthma? Scientific World Journal 7: 1082-1089, 2007.
23. Tamaoki J, Isono K, Taira M, Tagaya E, Nakata J, Kawatani K and Nagai A: Role of regular treatment with inhaled corticosteroid or leukotriene receptor antagonist in mild intermittent asthma. Allergy Asthma Proc 29: 189-196, 2008.

24. Wongtim S, Mogmued S, Chareonlap P and Limthongkul S: Effect of inhaled corticosteroids on bronchial hyperresponsiveness in patients with mild asthma. Asian Pac J Allergy Immunol 13: 81-85, 1995.

25. Haahtela T, Järvinen M, Kava T, Kiviranta K, Koskinen S, Lehtonen K, Nikander K, Persson T, Selroos O, Sovijärvi A, et al: Effects of reducing or discontinuing inhaled budesonide in patients with mild asthma. N Engl J Med 331: 700-705, 1994.

26. Papi A: Treatment strategies in mild asthma. Curr Opin Pulm Med 15: 29-34, 2009.

27. Koh MS and Irving LB: The natural history of asthma from childhood to adulthood. Int J Clin Pract 61: 1371-1374, 2007.

28. Fuhlbrigge AL and Kelly HW: Inhaled corticosteroids in children: Effects on bone mineral density and growth. Lancet Respir Med 2: 487-496, 2014

29. O'Byrne PM, Barnes PJ, Rodriguez-Roisin R, Runnerstrom E, Sandstrom T, Svensson K and Tattersfield A: Low dose inhaled budesonide and formoterol in mild persistent asthma: The OPTIMA randomized trial. Am J Respir Crit Care Med 164: 1392-1397, 2001

30. Busse WW, Pedersen S, Pauwels RA, Tan WC, Chen YZ, Lamm CJ and O'Byrne PM; START Investigators Group: The inhaled steroid treatment as regular therapy in early asthma (START) study 5-year follow-up: Effectiveness of early intervention with budesonide in mild persistent asthma. J Allergy Clin Immunol 121: 1167-1174, 2008.

31. Juniper EF, Kline PA, Vanzieleghem MA, Ramsdale EH, O'Byrne PM and Hargreave FE: Effect of long-term treatment with an inhaled corticosteroid (budesonide) on airway hyperresponsiveness and clinical asthma in nonsteroid-dependent asthmatics. Am Rev Respir Dis 142: 832-836, 1990.

32. Lemière C, Ernst P, Olivenstein R, Yamauchi Y, Govindaraju K, Ludwig MS, Martin JG and Hamid Q: Airway inflammation assessed by invasive and noninvasive means in severe asthma: Eosinophilic and noneosinophilic phenotypes. J Allergy Clin Immunol 118: 1033-1039, 2006.

33. Green RH, Brightling CE, Pavord ID and Wardlaw AJ: Management of asthma in adults: Current therapy and future directions. Postgrad Med J 79: 259-267, 2003. 